\title{
Incidence, Management, and Outcomes of Chylothorax after Lung Transplantation: A Single-center Experience
}

\author{
Samuel Jacob ${ }^{1}$, Axel Meneses ${ }^{2}$, Kevin Landolfo ${ }^{1}$, Magdy El-Sayed Ahmed ${ }^{1}$, Ian A. Makey ${ }^{3}$, Si M. Pham ${ }^{1}$, \\ Mathew Thomas ${ }^{1}$ \\ 1. Cardiothoracic Surgery, Mayo Clinic, Jacksonville, USA 2. Cardiothoacic Surgery, Mayo Clinic, Jacksonville, USA 3. \\ Cardiothoraic Surgery, Mayo Clinic, Jacksonville, USA
}

Corresponding author: Mathew Thomas, thomas.mathew@mayo.edu

\section{Abstract \\ Background}

The objective of this study was to determine the incidence and outcomes of chylothorax after lung transplantation.

\section{Methods}

We conducted a retrospective review of our institutional lung transplant registry of 504 adult transplantations done from 2001 to 2015 and identified seven patients (1.38\%) with chylothorax. Electronic health records were then analyzed to determine demographics, indications for surgery, management, and outcomes. Survival curves were plotted using the Kaplan-Meier method.

\section{Results}

Chylothorax presented in the first week in four (62.5\%) patients, and approximately one month later in the remaining three. Nonsurgical management was initially attempted in all patients and succeeded in three (42.9\%). Elective surgical ligation of the thoracic duct (LTD) was successful in two (66.7\%) out of three patients in whom it was performed. One patient required emergent reoperation for clamshell thoracotomy dehiscence from severe chylothorax. Thoracic duct embolization was attempted but unsuccessful in two patients. Subsequently, one of these patients received a peritoneal-venous shunt and the other underwent LTD. Chylothorax permanently resolved in six patients (85.7\%). There were no mortalities directly related to chylothorax. The median time to resolution was 11 days (range: 7-60). The mean survival in months for chylothorax patients was 29.2 (SE 3.1) and 78.2 (SE 2.9) for the remaining patients $(p=0.37$ ). The median survival was not reached for the chylothorax group and was 71.8 months (95\% CI: 58.0-83.9) for the rest.

Received 07/03/2019

Review began 07/13/2019 Review ended 07/15/2019 Published 07/22/2019

() Copyright 2019

Jacob et al. This is an open access article distributed under the terms of the Creative Commons Attribution License CC-BY 3.0., which permits unrestricted use, distribution, and reproduction in any medium, provided the original author and source are credited.

\section{Conclusion}

Chylothorax is rare after lung transplantation but can lead to major comorbidities and prolonged hospital stay. In our experience, nonsurgical management was successful in up to $40 \%$ of patients. LTD should be considered in those who fail conservative management.

Categories: Cardiac/Thoracic/Vascular Surgery, Medical Education, Transplantation Keywords: lung transplantation, chylothorax, complications, management

\section{Introduction}

A high-output chylothorax is a therapeutic challenge as well as a life-threating complication secondary to persistent drainage of lymph fluids, resulting in immune suppression, malnutrition and electrolytes abnormalities. Although $49 \%$ to $54 \%$ of the chylothorax is caused by surgery or an invasive procedure, the reported overall incidence of postoperative chylothorax remains very low [1-2]. In an analysis of over 11,000 patients who had general thoracic procedures done at the Mayo Clinic in Minnesota, only $0.42 \%$ developed chylothorax, while another study from the University of Alabama reported an incidence of $1.4 \%$ after lung resection and mediastinal lymph node dissection [3-4]. The exact incidence of chylothorax after lung transplantation has not been studied in large populations but has been reported in the range of $<1 \%$ to $11 \%$ in smaller cohorts that included some heart-lung transplant recipients [5-8]. Our study was designed to determine the incidence, management, and outcomes of post-operative chylothorax in lung transplant recipients at our institution.

\section{Materials And Methods}

The Mayo Clinic Institutional Review Board approved the study and waived informed consent due to minimal risk. We queried our prospectively maintained institutional transplantation registry to identify 


\section{Cureus}

adult ( $\geqslant 18$ years of age) lung transplant recipients from 2001 to 2015 who had a documented clinical or laboratory diagnosis of postoperative chylothorax, defined as occurring within two months after transplantation. Heart-lung recipients were excluded from the study. A retrospective review of the electronic health records of these patients was performed. Data variables collected included demographics, indication for transplantation, surgical approach and type of transplant (unilateral or bilateral), management and complications of chylothorax. Time to resolution of chylothorax was defined as the time (in days) from the first diagnosis of chylothorax to the removal of the last chest drain without the need for additional drainage. JMP ${ }^{\circledR}$ Pro 10.0.0 statistical software was used to estimate survival curves of the cohort with chylothorax and the rest of the lung transplant population at our institution using the Kaplan-Meier method; the survival curves of the two groups were then compared using the log-rank test method. Survival times are reported as mean (standard error) and median values. Statistical significance was accepted as $P<$ 0.05 .

\section{Results}

During the study period, postoperative chylothorax was documented in seven (1.38\%) out of 504 lung transplantations that were performed from 2001 to 2015 . These included four (57\%) men and three (53\%) women with a median age of 58 years (range: $37-67$ years). The most common indication for transplantation was pulmonary fibrosis (five patients; 71.4\%). All patients excepting one received bilateral lung transplantation. One patient underwent bilateral re-transplantation for graft failure one year after previous bilateral lung transplantation. The average recipient body mass index (BMI) was in the overweight range at $27.2 \pm 4$. Patient demographics and chylothorax characteristics are shown in Table 1.

\begin{tabular}{|c|c|c|c|c|c|c|c|c|c|c|c|}
\hline $\begin{array}{l}\text { Pt } \\
\text { No. }\end{array}$ & Age & Sex & Diagnosis & $\begin{array}{l}\text { Lung transplant } \\
\text { type }\end{array}$ & $\begin{array}{l}\text { Surgical } \\
\text { approach }\end{array}$ & CPB & $\begin{array}{l}\text { Side of } \\
\text { chylothorax }\end{array}$ & $\begin{array}{l}\text { Time from transplant to } \\
\text { presentation (days) }\end{array}$ & $\begin{array}{l}\text { Resolution time } \\
\text { (days) }\end{array}$ & $\begin{array}{l}\text { Survivalin } \\
\text { months }\end{array}$ & $\begin{array}{l}\text { Current survival } \\
\text { status }\end{array}$ \\
\hline 1 & 48 & M & Silicosis & Bilateral & Clamshell & No & Bilateral & 7 & 22 & 189 & Alive \\
\hline 2 & 66 & $\mathrm{~F}$ & $\begin{array}{l}\text { Pulmonary } \\
\text { Fibrosis }\end{array}$ & Unilateral [R] & PLT & Yes & Unilateral [R] & 35 & 14 & 31 & Deceased \\
\hline 3 & 67 & M & $\begin{array}{l}\text { Pulmonary } \\
\text { Fibrosis }\end{array}$ & $\begin{array}{l}\text { Bilateral } \\
\text { (retransplant) }\end{array}$ & PLT & No & Bilateral & 30 & 7 & 17 & Deceased \\
\hline 4 & 63 & $M$ & Bronchiectasis & Bilateral & PLT & No & Unilateral $[\mathrm{R}]$ & 4 & 8 & 91 & Alive \\
\hline 5 & 58 & $M$ & Fibrosis & Bilateral & PLT & No & Unilateral [R] & 3 & 7 & 61 & Alive \\
\hline 6 & 37 & $\mathrm{~F}$ & LAM & Bilateral & Clamshell & Yes & Unilateral $[\mathrm{R}]$ & 6 & Unresolved & 27 & Alive \\
\hline 7 & 44 & $\mathrm{~F}$ & $\begin{array}{l}\text { Pulmonary } \\
\text { Fibrosis }\end{array}$ & Bilateral & PLT & Yes & Unilateral $[\mathrm{R}]$ & 35 & 60 & 18 & Alive \\
\hline
\end{tabular}

\section{TABLE 1: Patient demographics and characteristics of chylothorax}

CPB, cardiopulmonary bypass; PLT, posterolateral thoracotomy; LAM, lymphangioleiomyomatosis

Presentation, management, and outcomes of chylothorax are summarized in Table 2. 


\section{Cureus}

\begin{tabular}{|c|c|c|c|c|c|c|c|}
\hline No & Presentation & Diet & TPN? & $\begin{array}{l}\text { Total } \\
\text { TPN } \\
\text { time }\end{array}$ & Octreotide? & $\begin{array}{l}\text { Type(s) of } \\
\text { intervention }\end{array}$ & $\begin{array}{l}\text { Final } \\
\text { status }\end{array}$ \\
\hline 1 & $\begin{array}{l}\text { Chylous chest tube drainage, acute } \\
\text { clamshell thoracotomy wound } \\
\text { dehiscence }\end{array}$ & $\begin{array}{l}\text { Chylothorax diet } \\
\text { before surgery; NPO } \\
\text { followed by low fat } \\
\text { diet after surgery }\end{array}$ & Yes & 14 & No & $\begin{array}{l}\text { Reoperation with } \\
\text { washout and repair of } \\
\text { sternal dehiscence }\end{array}$ & Resolved \\
\hline 2 & $\begin{array}{l}\text { General weakness, malnutrition, } \\
\text { pleural effusion }\end{array}$ & Non fat diet & No & N/A & Yes & $\begin{array}{l}\text { Thoracentesis, Pigtail } \\
\text { thoracic drain }\end{array}$ & Resolved \\
\hline 3 & $\begin{array}{l}\text { Extreme fatigue, anorexia, failure to } \\
\text { thrive, pleural effusion }\end{array}$ & NPO then low fat diet & Yes & 15 & No & $\begin{array}{l}\text { Bilateral pigtail } \\
\text { thoracic drain }\end{array}$ & Resolved \\
\hline 4 & Chylous chest tube drainage & NPO & Yes & 5 & Yes & $\begin{array}{l}\text { LTD and oversewing } \\
\text { of leak }\end{array}$ & Resolved \\
\hline 5 & Chylous chest tube drainage & Chylothorax diet & No & NA & Yes & None & Resolved \\
\hline 6 & $\begin{array}{l}\text { Chylous chest tube drainage, } \\
\text { Pericardial effusion, large volume } \\
\text { pleural effusions, Denver shunt } \\
\text { thrombus, empyema, chylous ascites }\end{array}$ & $\begin{array}{l}\text { NPO then } \\
\text { chylothorax diet }\end{array}$ & Yes & 23 & Yes & $\begin{array}{l}\text { Attempted TD } \\
\text { embolization; Surgery } \\
\text { - LTD, pleurodesis, } \\
\text { Denver shunt; } \\
\text { paracentesis, multiple } \\
\text { thoracentesis and } \\
\text { drains }\end{array}$ & Persistent \\
\hline 7 & Malnutrition, pleural effusion & $\begin{array}{l}\text { Chylothorax diet then } \\
\text { NPO; resumed } \\
\text { chylothorax after } \\
\text { surgery }\end{array}$ & Yes & 31 & Yes & $\begin{array}{l}\text { Pigtail thoracic drain; } \\
\text { attempted TD } \\
\text { embolization; Surgery } \\
\text { - LTD }\end{array}$ & Resolved \\
\hline
\end{tabular}

\section{TABLE 2: Presentation, management, and outcomes of chylothorax}

TPN, total parenteral nutrition; NPO, nil per os; LTD, ligation of thoracic duct

The majority (five patients; 71.4\%) developed only a unilateral right-sided chylous effusion. Chylothorax was diagnosed in the first week after transplantation in four patients who presented with chylous chest tube drainage, while in the remaining three, the presentation and diagnosis were delayed until approximately one month after surgery. One patient developed a milky chest tube output seven days after transplantation and was managed with a chylothorax diet but had acute wound dehiscence of his clamshell thoracotomy incision one week later with chyle draining through the wound. All three patients with delayed presentations were readmitted with failure to thrive and poor appetite a month after transplantation and on workup were found to have large pleural effusions. The chylothorax diagnosis was confirmed by pleural fluid analysis for triglycerides and chylomicrons in two patients, while in the other five, the diagnosis was clinically based on the milky appearance of chest tube effluent.

\section{Management}

Non-operative management was initially attempted in all seven patients and resulted in complete resolution of chylothorax in three (42.9\%). Successful nonsurgical management included a combination of pigtail catheter drainage, nothing by mouth (nil per os, NPO), total parenteral nutrition (TPN), and subcutaneous octreotide in two patients, while only octreotide and a chylothorax diet (low-fat, mediumchain triglyceride diet) were required in the third patient who already had chest tubes.

The remaining four patients underwent surgery after failure of conservative management (Table 2) and included three elective TD ligations and one emergent operation. The chylothorax successfully resolved after duct ligation in two of the three patients (66.7\%) even though only one had an intraoperatively visible site of chyle leak on the TD. The fourth patient underwent emergent surgical exploration for clamshell thoracotomy wound dehiscence, with washout of the pleural spaces and rewiring of the sternum. No TD ligation was performed, and postoperatively, he was managed with two weeks of NPO and TPN before his chylothorax completely resolved.

TD lymphangiography and embolization were unsuccessfully attempted in two patients, one of whom (patient seven ) had earlier failed both conservative management and surgical ligation of the TD. The second 
patient subsequently underwent surgical TD ligation with successful resolution of chylothorax. Subcutaneous octreotide was given to five out of seven patients but non-uniform dosing and duration of the drug limit analysis of whether it contributed to the resolution of chylothorax.

\section{Outcomes}

Complete resolution of chylothorax was seen in six (85.7\%) patients. Patient seven who underwent bilateral transplantation for lymphangioleiomyomatosis (LAM) failed multiple interventions including open TD ligation, followed by talc and mechanical pleurodesis. She developed a chylous pericardial effusion that required the creation of a surgical pericardial window to the peritoneal cavity. Prolonged TPN, NPO, octreotide therapy, and attempted embolization of the TD were also unsuccessful. Subsequently, she developed chylous ascites and underwent intra-abdominal lymphatics embolization with resolution for one year, which reoccurred, and a peritoneo-jugulovenous (Denver) shunt was placed, which helped control the effusion and ascites and the shunt was removed later. The patient eventually developed sepsis secondary to Staphylococcal empyema. The initial Denver shunt became non-functional due to thrombus and was removed. Her chylothorax recurred and was managed with multiple thoracentesis and large volume paracentesis procedures until the Denver shunt was replaced. She has had multiple admissions since then for various transplant- and chylothorax-related complications. She underwent intra-abdominal lymphatics embolization. In addition, she failed therapy with Sirolimus and Everolimus before she underwent ligation.

The median time for the resolution of chylothorax was 11 days (range: 7-60 days) and the median length of stay was 55 days (range 9-104 days). The mean survival for patients with chylothorax was 29.2 (3.1) months, compared to 78.2 (2.9) months for the rest of the transplant population $(p=0.37)$. The median survival was not reached for the chylothorax group and was 71.8 months (95\% CI: 58.0-83.9) for the remaining patients.

\section{Discussion}

As observed in our study, chylothorax is an uncommon complication after lung transplantation but when present can lead to significant morbidity and prolonged hospital stay. Furthermore, patients with postoperative chylothorax often require additional major interventions including re-operations which add to healthcare costs and increase the risks of further complications. Pre-operatively identifying recipients at higher risk for chylothorax may be helpful in discussing the implications and management of this major complication with the patient and their caregivers. The current scarcity of published data about chylothorax after lung transplantation makes it difficult to understand the true course and impact of this complication in this particular group of patients. The results of our study indicate that long-term survival is not adversely affected in patients with post-operative chylothorax.

The mechanism of chylothorax after lung transplantation is probably multifactorial. Uncomplicated lung transplant operations do not usually involve dissection along the normal course of the TD, and hence direct intraoperative injury to the TD is uncommon but may occur in cases where prior infection or pleurodesis obliterates anatomical planes. All the patients in our study were reported to have severe pleural adhesions in their operative notes, placing them at a higher risk of chylothorax. Other plausible reasons for posttransplant chylothorax may include injury to an aberrant TD or lymph leak from disruption of dilated perihilar or mediastinal lymphatics and lymph nodes [9]. Partial or complete obstruction of superior vena cava or subclavian veins due to long-standing indwelling central venous catheters raises the pressure in the lymphatics, thereby making them fragile and increases the risk for chyle leak. Lymphangioleiomyomatosis (LAM) is another condition with a high risk for chylothorax because of the extensive network of lymphatics that are present within the chest in these patients; the reported incidence of post-transplant chylothorax is around $7 \%$ to $8 \%$ in LAM patients [10-12]. In a previously published study of 12 patients with LAM who underwent lung transplantation at our institution, one patient (8.3\%) developed post-operative chylothorax [13]. As described above, chylothorax in our patient with LAM has been the most challenging to manage, having failed multiple interventions and currently controlled with Denver shunt.

Post-operative chylothorax can be extremely challenging to manage but resolved in about $40 \%$ of patients in our study who were managed initially with non-operative methods. Adequate chest drainage and prevention of dehydration, electrolyte imbalance, malnutrition, and infections are the goals of non-surgical management [14]. Both supportive and directed therapies are essential in ensuring good outcomes in these patients who are often debilitated and immunocompromised. Our current algorithm for management of post-operative chylothorax is shown in Figure 1. 


\section{Cureus}

Figure 1: Algorithm for management of chylothorax

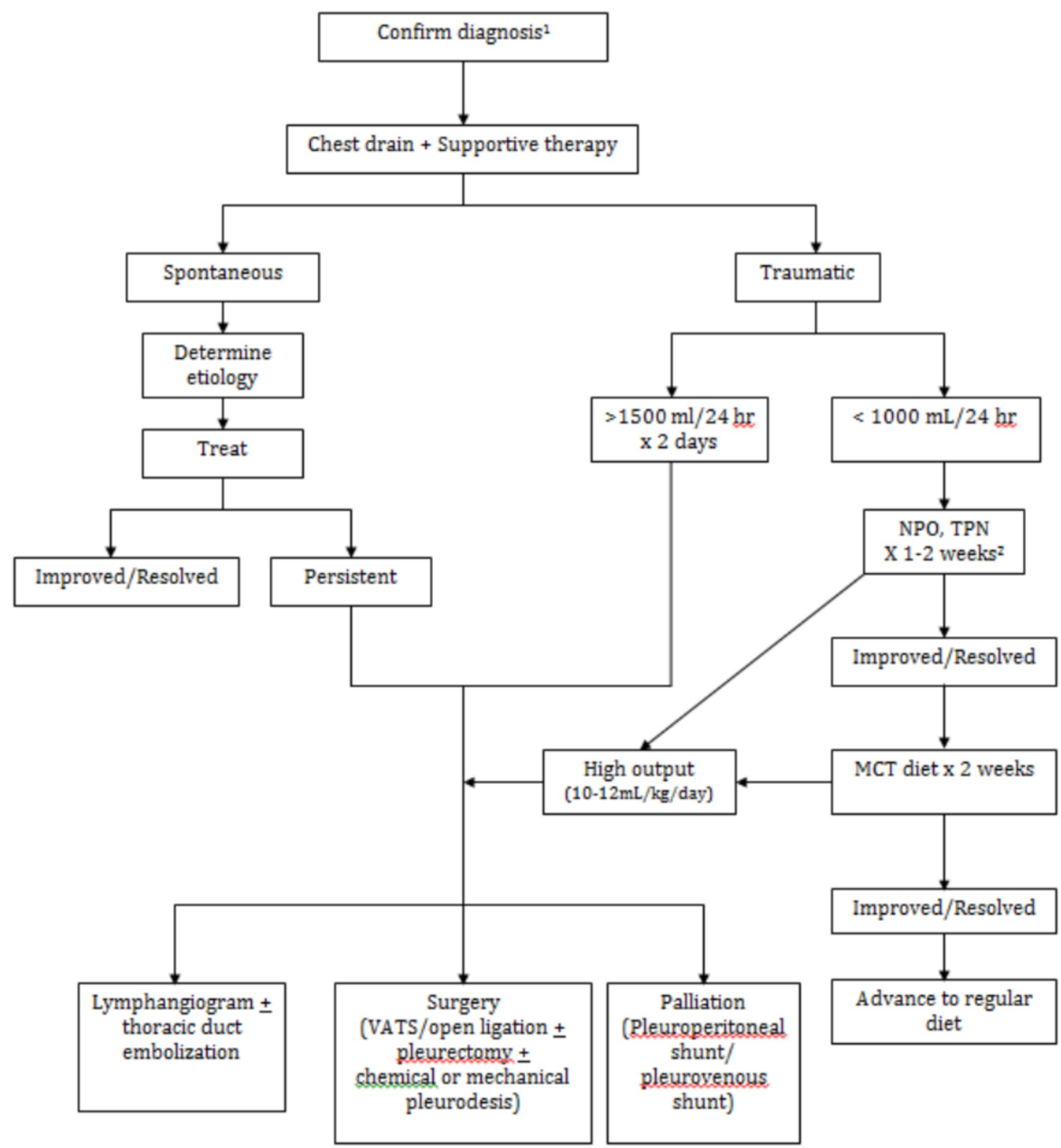

'Pleural fluid is sent for triglycerides and chylomicrons analysis if clinical diagnosis is equivocal. ${ }^{2}$ When initial chylothorax output is low ( $\left.<300 \mathrm{~mL} / 24 \mathrm{hrs}\right)$, a non-fat or chylothorax diet trial can be trialed. NPO: Nil per 05; TPN: total parenteral nutrition; MCT: medium chain triglvderide VATS: video-assisted thporacoscopic surgery

\section{FIGURE 1: Algorithm for management of chylothorax}

${ }^{1}$ Pleural fluid is sent for triglycerides and chylomicrons analysis if the clinical diagnosis is equivocal.

${ }^{2}$ When initial chylothorax output is low ( $<300 \mathrm{~mL} / 24$ hours), a non-fat or chylothorax diet trial can be trialed.

NPO, nil per os; TPN, total parenteral nutrition; MCT, medium-chain triglyceride; VATS, video-assisted thoracoscopic surgery

Chylothorax is often diagnosed based on high volume chest tube output with a milky appearance of pleural fluid. Chemical analysis of the pleural fluid for triglycerides and chylomicrons is performed only if there is any doubt about the diagnosis. We considered persistent high output (average daily volume: $>1500 \mathrm{~mL} / \mathrm{day}$ for two days or $>1000 \mathrm{~mL} /$ day for two days) in the early post-operative period or after a longer period of nonsurgical therapy (average daily volume: $10-12 \mathrm{~mL} / \mathrm{kg} /$ day for two weeks) as an indication for active intervention [3,15]. A prior study of post-operative chylothorax in non-transplant patients showed $49 \%$ success with non-surgical management [1]. Surgical ligation of the thoracic duct has been historically considered the definitive treatment for post-operative chylothorax that fails conservative management and has been reported to be exceptionally successful [15-16]. TD embolization is a less invasive alternative to surgical ligation but could not be successfully performed in the two patients in our patient cohort due to difficulties in canalizing the duct. Other authors have reported successful clinical resolution of chylothorax in $72 \%$ to $90 \%$ of patients with embolization when the TD can be canalized [17-18]. Other surgical options include mechanical and chemical pleurodesis or even a parietal pleurectomy. Pleuroperitoneal and peritoneovenous shunts are palliative therapies that provide a pathway for recycling the chylothorax into the peritoneal cavity or venous system. In patients with chylous ascites, the pleuroperitoneal shunt is contraindicated. Pleurovenous shunts have been reported to be successful in a few cases of refractory 
chylothorax by other authors [12,19-20]. As noted in the LAM patient in our study, peritoneovenous or pleurovenous shunts may occasionally fail requiring replacement.

Our study has certain limitations, which include its retrospective nature even though the data were collected prospectively. It is possible that minor chyle leaks may have occurred in other lung recipients and may have spontaneously stopped prior to being clinically detected. As a heterogenous group, lung transplant recipients have multiple comorbidities that may confound the true course of post-operative chylothorax. Treatment and timing of interventions were not uniform in all patients and this makes it challenging to make strong recommendations regarding the management of chylothorax except to suggest that conservative management still plays a significant role in initial management. Although the number of patients with chylothorax in our study is small, it provides an important perspective into an uncommon but potentially devastating complication that to the best of our knowledge has not been analyzed before in a large, single institutional group of lung transplant recipients.

\section{Conclusions}

Chylothorax is a rare complication after adult lung transplantation that can lead to major comorbidities and prolonged hospital stay. When managed appropriately, it has no significant effect on long-term survival. Nonsurgical management should be attempted initially and may be successful in up to $40 \%$ of patients. Surgical ligation of the thoracic duct should be considered in patients who have failed conservative management.

\section{Additional Information \\ Disclosures}

Human subjects: All authors have confirmed that this study did not involve human participants or tissue. Animal subjects: All authors have confirmed that this study did not involve animal subjects or tissue. Conflicts of interest: In compliance with the ICMJE uniform disclosure form, all authors declare the following: Payment/services info: All authors have declared that no financial support was received from any organization for the submitted work. Financial relationships: All authors have declared that they have no financial relationships at present or within the previous three years with any organizations that might have an interest in the submitted work. Other relationships: All authors have declared that there are no other relationships or activities that could appear to have influenced the submitted work.

\section{References}

1. Maldonado F, Cartin-Ceba R, Hawkins FJ, Ryu JH: Medical and surgical management of chylothorax and associated outcomes. Am J Med Sci. 2010, 339:314-318. 10.1097/MAJ.0b013e3181cdcd6c

2. Doerr CH, Allen MS, Nichols FC, 3rd, Ryu JH: Etiology of chylothorax in 203 patients . Mayo Clin Proc. 2005, 80:867-870. 10.4065/80.7.867

3. Cerfolio RJ, Allen MS, Deschamps C, Trastek VF, Pairolero PC: Postoperative chylothorax. J Thorac Cardiovasc Surg. 1996, 112:1361-1365. 10.1016/S0022-5223(96)70152-6

4. Bryant AS, Minnich DJ, Wei B, Cerfolio RJ: The incidence and management of postoperative chylothorax after pulmonary resection and thoracic mediastinal lymph node dissection. Ann Thorac Surg. 2014, 98:232235. 10.1016/j.athoracsur.2014.03.003

5. Herridge MS, de Hoyos AL, Chaparro C, Winton TL, Kesten S, Maurer JR: Pleural complications in lung transplant recipients. J Thorac Cardiovasc Surg. 1995, 110:22-26. 10.1016/S0022-5223(05)80005-4

6. Ferrer J, Roldan J, Roman A, et al.: Acute and chronic pleural complications in lung transplantation . J Heart Lung Transplant. 2003, 22:1217-1225.

7. Haam SJ, Lee DY, Paik HC: An overview of lung transplantation in Korea . Transplant Proc. 2008, 40:26202622. 10.1016/j.transproceed.2008.07.114

8. Tomasz M Ziedalski , Thomas A Raffin , Daniel Y Sze , et al.: Chylothorax after heart/lung transplantation. J Heart Lung Transplant. 2004, 23:627-631. 10.1016/S1053-2498(03)00227-4

9. Boehler A, Speich R, Russi EW, Weder W: Lung transplantation for lymphangioleiomyomatosis. N Engl J Med. 1996, 335:1275-1280. 10.1056/NEJM199610243351704

10. Benden C, Rea F, Behr J, et al.: Lung transplantation for lymphangioleiomyomatosis: the European experience. J Heart Lung Transplant. 2009, 28:1-7. 10.1016/j.healun.2008.09.014

11. Ryu JH, Doerr CH, Fisher SD, Olson EJ, Sahn SA: Chylothorax in lymphangioleiomyomatosis . Chest. 2003, 123:623-627. 10.1378/chest.123.2.623

12. Fremont RD, Milstone AP, Light RW, Ninan M: Chylothoraces after lung transplantation for lymphangioleiomyomatosis: review of the literature and utilization of a pleurovenous shunt. J Heart Lung Transplant. 2007, 26:953-955. 10.1016/j.healun.2007.07.008

13. Ussavarungsi K, Hu X, Scott JP, et al.: Mayo Clinic experience of lung transplantation in pulmonary lymphangioleiomyomatosis. Respir Med. 2015, 109:1354-1359. 10.1016/j.rmed.2015.08.014

14. Doerr CH, Miller DL, Ryu JH: Chylothorax. Semin Respir Crit Care Med. 2001, 22:617-626. 10.1055/s-200118797

15. Patterson GA, Todd TR, Delarue NC, Ilves R, Pearson FG, Cooper JD: Supradiaphragmatic ligation of the thoracic duct in intractable chylous fistula. Ann Thorac Surg. 1981, 32:44-49. 10.1016/s00034975(10)61372-0

16. Christodoulou M, Ris HB, Pezzetta E: Video-assisted right supradiaphragmatic thoracic duct ligation for non-traumatic recurrent chylothorax. Eur J Cardiothorac Surg. 2006, 29:810-814. 10.1016/j.ejcts.2006.01.064 


\section{Cureus}

17. Pamaeth V, Stecker M, Schenker M, at el: Thoracic duct embolization and disruption for treatment of chylous effusions: experience with 105 patients. J Vasc Interv Radiol. 2014, 25:1398-1404.

10.1016/j.jvir.2014.03.027

18. Itkin M, Kucharczuk JC, Kwak A, et al.: Nonoperative thoracic duct embolization for traumatic thoracic duct leak: experience in 109 patients. J Thorac Cardiovasc Surg. 2010, 139:584-589. 10.1016/j.jtcvs.2009.11.025

19. Artemiou O, Marta GM, Klepetko W, Wolner E, Muller MR: Pleurovenous shunting in the treatment of nonmalignant pleural effusion. Ann Thorac Surg. 2003, 76:231-233. 10.1016/s0003-4975(03)00193-0

20. Tanaka E, Matsumoto K, Shindo T, Taguchi Y: Implantation of a pleurovenous shunt for massive chylothorax in a patient with yellow nail syndrome. Thorax. 2005, 60:254-255. 10.1136/thx.2003.015925 